\title{
The Effects of Anorexia Nervosa on Bone Metabolism in Female Adolescents*
}

\author{
LESLIE A. SOYKA, STEVEN GRINSPOON, LYNNE L. LEVITSKY, \\ DAVID B. HERZOG, AND ANNE KLIBANSKI
}

\author{
Neuroendocrine Unit (L.A.S., S.G., A.K.), Pediatric Endocrine Unit (L.A.S., L.L.L.), and Eating \\ Disorders Unit (D.B.H.), Massachusetts General Hospital and Harvard Medical School, Boston, \\ Massachusetts 02114
}

\begin{abstract}
Osteopenia is a frequent, often persistent, complication of anorexia nervosa (AN) in adolescent girls and occurs during a critical time in bone development. Little is known about bone metabolism in this patient population. Therefore, we measured bone density (BMD) and body composition by dual energy x-ray absorptiometry, nutritional status, bone turnover, calcium, and hormonal status in 19 adolescent girls with $\mathrm{AN}$ (mean $\pm \mathrm{SEM}, 16.0 \pm 0.4 \mathrm{yr}$ ) and 19 bone age-matched controls. The mean duration of AN was $19 \pm 5$ months. Spinal (L1-L4) osteopenia was common in AN. Lumbar anterioposterior BMD was more than $1 \mathrm{SD}$ below the mean in $42 \%$ of patients, and lateral spine BMD was more than $1 \mathrm{sD}$ below in $63 \%$ of patients compared with controls. Lean body mass significantly predicted lumbar bone mineral content $(\mathrm{r}=0.75 ; P<0.0001)$ in controls only. In AN, duration of illness was the most significant predictor of spinal BMD (lumbar: $\mathrm{r}=$ $-0.44 ; P=0.06$; lateral: $\mathrm{r}=-0.59 ; P=0.008)$. AN adolescents with mature BA (15 yr and greater) were hypogonadal [estradiol, $16.2 \pm$ 1.9 vs. $23.3 \pm 1.6 \mathrm{pg} / \mathrm{mL}(P=0.01)$; free testosterone, $0.70 \pm 0.17 \mathrm{vs}$. $1.36 \pm 0.14 \mathrm{pg} / \mathrm{mL}(P=0.01)]$ although dehydroepiandrosterone sulfate and urinary free cortisol levels did not differ. Leptin levels were
\end{abstract}

reduced in $\mathrm{AN}(2.9 \pm 2.1$ vs. $16.5 \pm 1.8 \mathrm{ng} / \mathrm{mL} ; P<0.0001)$. Insulinlike growth factor I (IGF-I) was reduced in AN to $50 \%$ of control levels $(219 \pm 41$ vs. $511 \pm 35 \mathrm{ng} / \mathrm{mL} ; P<0.0001)$ and correlated with all measures of nutritional status, particularly leptin $(\mathrm{r}=0.80 ; P<$ 0.0001). Surrogate markers of bone formation, serum osteocalcin (OC) and bone-specific alkaline phosphatase (BSAP), were significantly $(P=0.02)$ reduced in AN vs. controls (OC, $39.1 \pm 6.4$ vs. $59.2 \pm 5.2$ $\mathrm{ng} / \mathrm{mL}$; BSAP, $27.9 \pm 4.0$ vs. $40.6 \pm 3.4 \mathrm{U} / \mathrm{L})$. The majority of the variation in bone formation in $\mathrm{AN}$ was due to IGF-I levels (OC: $\mathrm{r}^{2}=$ $0.72 ; P=0.002$; BSAP: $\mathrm{r}^{2}=0.53 ; P=0.01$ ) in stepwise regression analyses. Bone resorption was comparable in patients and controls. These data demonstrate that bone formation is reduced and uncoupled to bone resorption in mature adolescents with AN in association with low bone density. Lean body mass was a significant predictor of $\mathrm{BMD}$ in controls, but not $\mathrm{AN}$ patients. The major correlate of bone formation in AN was the nutritionally dependent bone trophic factor, IGF-I. Reduced IGF-I during the critical period of bone mineral accumulation may be an important factor in the development of osteopenia in adolescents with AN. (J Clin Endocrinol Metab 84: 4489 4496, 1999)
A NOREXIA NERVOSA (AN) is an increasingly common disorder in adolescent girls, with a prevalence of $0.2-$ $1.0 \%$ in Western societies $(1,2)$. Osteopenia is a frequent and often persistent complication of AN in this young population (3-6), leading to clinical fractures and increased fracture risk throughout life $(7,8)$. A severe degree of decreased bone mass has been reported even in young adolescents with a brief duration of illness (3). Adolescence represents a critical time in bone metabolism, as most bone mineral is accumulated during the teenage years, and deficits incurred during this time may be permanent. Therefore, an understanding of the factors that impact bone density during this time period is of particular importance.

Bone density and bone metabolism change dramatically during adolescence, and the onset of AN during this critical time may interfere with achievement of peak bone mass. In addition, significant changes in body weight and composition, pubertal development, and pubertal hormones, such as estradiol and insulin-like growth factor I (IGF-I), occur in AN and may impact bone metabolism. The effect of AN on bone

Received June 11, 1999. Accepted September 17, 1999.

Address all correspondence and requests for reprints to: Dr. Anne Klibanski, Neuroendocrine Unit, Bulfinch 457, Massachusetts General Hospital, Boston, Massachusetts 02114.

* This work was supported in part by NIH Grants R01-DK-52625, M01-RR-01066, R01-3833, the Genentech Foundation for Growth and Development, and the Harvard Eating Disorders Center. turnover in adolescent girls is poorly understood. Limited data are available $(9,10)$, and prior studies in adolescents with AN have been limited by the small numbers of subjects and the lack of information about specific biochemical markers of bone turnover, including simultaneous measurements of formation and resorption. Moreover, previous studies have included subjects of a broad age range from early adolescence to young adulthood. Finally, pubertal and skeletal maturation have not been measured in assessments of bone density, even though bone density correlates more with pubertal stage and bone age (BA) than chronological age (CA) $(11,12)$.

The purpose of this study was to further characterize bone metabolism and potential mechanisms of osteopenia in adolescents with AN in a cohort of adolescent females in whom bone density, biochemical indices of bone turnover, nutritional status, and pubertal hormones were determined compared with those in BA-matched controls. Our data demonstrate significant osteopenia in adolescent girls with AN. Bone formation indices are significantly reduced in association with IGF-I and other nutritionally dependent factors in this population of patients, suggesting a profound effect of this disease on osteoblast function.

\section{Subjects}

\section{Subjects and Methods}

We studied 38 Caucasian adolescent girls, 19 with AN, and 19 healthy adolescents. The AN patients were $12.8-18.5$ yr of age. All met DSM IV 
criteria for AN, with duration since diagnosis ranging from 2-72 months. Only 1 patient had concomitant bulimia. All patients had either primary $(n=2)$ or secondary ( $n=12$; duration, 6-48 months) amenorrhea or were premenarchal $(\mathrm{n}=5)$. Two patients with secondary amenorrhea had taken estrogen previously (for 6-18 months), but not within 3 months of the study. Patients receiving hormonal or other medications known to affect bone metabolism were excluded. A history of traumatic bone fracture was reported during childhood or adolescence in $32 \%$ of AN patients, but none occurred within 6 months of the study. Subjects were recruited through mass mailings to primary health care providers and through collaboration with eating disorder programs in the greater Boston area.

A control group of 19 healthy Caucasian female adolescents, aged 13.1-17.8 yr, was recruited by advertisement in primary care providers' offices and community newspapers. All had a body mass index (BMI; kilograms per meter squared) between the 25th-90th percentile for age based on published standard charts (13). One control subject, $13.1 \mathrm{yr}$ old, was premenarchal. All postmenarchal adolescents had regular menstrual periods. None of the controls had a history of an eating disorder. Control subjects with a medical condition or receiving hormonal or other medications known to affect bone metabolism were excluded. A history of traumatic bone fracture during childhood or adolescence was reported in $42 \%$ of control subjects, but none occurred within 6 months of the study.

The study protocol was approved by the Massachusetts General Hospital subcommittee on human subjects, and informed consent was obtained from all subjects and their parents.

\section{Experimental protocol}

All subjects were evaluated during an out-patient visit at the General Clinical Research Center at Massachusetts General Hospital after a screening visit to determine eligibility and give instruction on collection of urine samples and completion of 4-day food records. A medical and menstrual history and physical examination were performed by a single investigator. All control subjects were studied during the early follicular phase of the menstrual cycle to control for the effects of cycle stage on biochemical and hormonal measurements. All AN and control subjects had their BA determined by $\mathrm{x}$-ray of the left hand and wrist by a single investigator using the methods of Greulich and Pyle (14).

Subjects' height was measured using a single stadiometer (average of triplicate measurements), and weight was measured in a hospital gown on an electronic scale. BMI was calculated, and BMI percentile was determined from published charts (13).

Subjects collected a 24-h and a 2-h second morning urine sample at home. All had fasting blood samples drawn at the same time of day (afternoon). Urine and serum samples were obtained for biochemical and hormonal measurements as outlined below. Bone density and body composition were assessed in all subjects.

\section{Classification of subjects by bone age}

For the analysis of biochemical parameters that are dependent on pubertal stage, such as gonadal steroids and markers of bone formation and resorption, we subdivided groups by maturity. Previous studies reported significant changes in bone turnover markers between girls in Tanner stages $2-3$ and $4-5(15,16)$. Tanner breast staging is difficult to assess in females with AN who are hypoestrogenemic and have breast atrophy, whereas BA provides more objective information on past and current maturation. We therefore subdivided subjects into immature $(\mathrm{BA},<15 \mathrm{yr}$ ) and mature (BA, $\geq 15 \mathrm{yr}$ ) groups. We used the cut-off BA of $15 \mathrm{yr}$ because this BA is mature, in that all epiphyses are near fusion, and $99 \%$ of final adult height has been attained according to the standards of Greulich and Pyle (14). Biochemical data are available for the mature group only, because there were insufficient numbers of immature subjects based on initial power calculations.

\section{Biochemical assessment}

Serum ionized calcium, phosphorus, TSH, dehydroepiandrosterone sulfate, and 24-h urinary free cortisol (UFC), calcium, and creatinine were measured through the hospital laboratory using previously described methods (17).
Serum estradiol $\left(\mathrm{E}_{2}\right)$ was measured by ultrasensitive RIA (Diagnostics Systems Laboratories, Inc., Webster, TX). The detection limit of the $\mathrm{E}_{2}$ assay is $2.2 \mathrm{pg} / \mathrm{mL}$, and the coefficient of variation is $6.5-8.9 \%$. Total and free testosterone $(\mathrm{T})$ were measured by RIA (Coat-A-Count, Diagnostic Products, Los Angeles, CA). Total T had a detection limit of $20 \mathrm{ng} / \mathrm{dL}$ and an intraassay coefficient of variation of $10-15 \%$, and free $\mathrm{T}$ had a detection limit of $0.57 \mathrm{pg} / \mathrm{mL}$ and an intraassay coefficient of variation of $3.2-4.3 \%$. Serum IGF-I was measured by acid-alcohol extraction using a RIA kit (Nichols Institute Diagnostics, San Juan Capistrano, CA), with a detection limit of $0.06 \mathrm{ng} / \mathrm{mL}$ and an intraassay coefficient of variation $2.4-3.0 \%$. Serum leptin was measured by RIA (Linco Research, Inc., St. Louis, MO) with a sensitivity of $0.5 \mathrm{ng} / \mathrm{mL}$ and an intraassay coefficient of variation of $3.4-8.3 \%$. Serum 25 -hydroxyvitamin $\mathrm{D}$ was measured by RIA (DiaSorin, Inc., Stillwater, MN), with a detection limit of $3 \mathrm{ng} / \mathrm{mL}$ and a coefficient of variation of $10-13 \%$. Serum intact PTH was measured by a two-site immunoradiometric assay (Nichols Institute Diagnostics, San Juan Capistrano, CA) with a detection limit of $1 \mathrm{pg} / \mathrm{mL}$ and an intraassay coefficient of variation of $1.8-3.4 \%$. Serum osteocalcin (OC) was measured using an immunoradiometric assay (Nichols Institute Diagnostics) with a sensitivity of $0.5 \mathrm{ng} / \mathrm{mL}$ and an intraassay coefficient of variation of $3.2-5.2 \%$. Bone-specific alkaline phosphatase (BSAP) was measured by immunoassay (Metra Biosystems, Mountain View, CA) with a sensitivity of $0.7 \mathrm{U} / \mathrm{L}$ and a coefficient of variation of $3.9-5.8 \%$. Carboxyl-terminal propeptide of type 1 procollagen was measured by RIA with an intraassay coefficient of variation of $2.1-3.2 \%$ (INCSTAR Corp., Stillwater, MN). Urinary deoxypyridinoline (DPD) and $\mathrm{N}$-telopeptide (NTX) were measured in a 2 - $\mathrm{h}$ second morning urine sample normalized for creatinine excretion. DPD was measured by competitive enzyme-linked immunoassay (Metra Biosystems) with a minimum detection limit of $1.1 \mathrm{nmol} / \mathrm{L}$ and an intraassay coefficient of variation of $4.3-8.4 \%$. NTX was measured by enzyme-linked immunosorbent assay (Ostex International, Inc., Seattle, WA) with a detection limit of $20 \mathrm{nmol}$ BCE and an intraassay coefficient of variation of $5-19 \%$. All samples were run in duplicate using a single kit.

\section{Bone density and body composition}

Total body and lumbar spine (L1-L4) bone densitites were measured using a QDR-4500 (Hologic, Inc., Waltham, MA). The SD for bone density measurement is $0.01 \mathrm{~g} / \mathrm{cm}^{2}$ and does not vary with bone density.

Whole body dual energy $x$-ray absorptiometry (DEXA) was performed using a Hologic, Inc. QDR-4500 densitometer to determine fat and lean body mass, which has been validated in children and young adults $(18,19)$.

\section{Nutritional assessment}

Nutritional intake data, including calorie, protein, fat, carbohydrate, and micronutrient content, were obtained through computer analysis (version 2, Nutrition Data Systems, Minneapolis, MN) of 4-day food records and history of dietary intake over the month before the study visit. Resting metabolic energy expenditure was performed using a metabolic cart (20). Typical exercise and activity of subjects over the past year were determined using a validated questionnaire (21).

\section{Statistical analysis}

Clinical, bone density, body composition, and biochemical data were analyzed with Student's $t$ test and compared by linear regression analysis. Stepwise regression analyses were performed to determine the relationship of anthropometric, body composition, and hormonal data to bone density and bone turnover. Significance was set at $P<0.05$ for all comparisons. Results are the mean \pm SEM unless otherwise indicated.

\section{Results \\ Clinical and anthropometric data}

Clinical and anthropometric data for patients and controls are summarized in Table 1. Patients were matched for BA (15.7 vs. $15.5 \mathrm{yr}$ ) with control subjects. CA was not significantly different between the AN and controls groups. However, BA compared with CA (BA/CA) was significantly 
TABLE 1. Clinical and anthropometric data

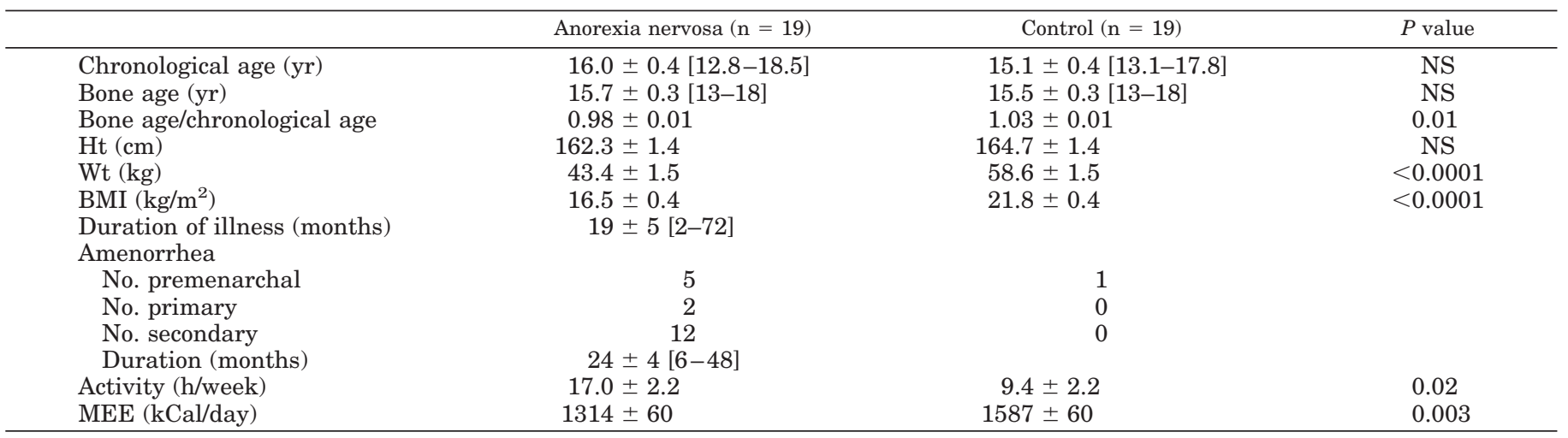

All values are expressed as the mean \pm SEM. Ranges are in brackets. The $P$ value is for comparison between anorexia nervosa and control subjects by Student's $t$ test. MEE, Resting metabolic energy expediture.

TABLE 2. Daily nutrient intake

\begin{tabular}{|c|c|c|c|}
\hline & Anorexia nervosa $(\mathrm{n}=17)$ & Control $(\mathrm{n}=18)$ & $P$ value \\
\hline Calories (KCal) & $1730 \pm 162[668-2913]$ & $2042 \pm 162$ [1395-4093] & NS \\
\hline$\% \mathrm{Cal}$ from fat & $20 \pm 2[16-33]$ & $28 \pm 2[16-41]$ & 0.005 \\
\hline Protein (g) & $72 \pm 6[31-128]$ & $70 \pm 6[40-122]$ & NS \\
\hline $\begin{array}{l}\text { Calcium }(\mathrm{mg}) \\
\%<\mathrm{RDA}\end{array}$ & $\begin{array}{c}1297 \pm 131[580-2333] \\
53 \%\end{array}$ & $\begin{array}{c}1238 \pm 128[589-2708] \\
67 \%\end{array}$ & NS \\
\hline $\begin{array}{l}\text { Vitamin D (IU) } \\
\%<\mathrm{RDA}\end{array}$ & $\begin{array}{c}423 \pm 62[112-1212] \\
53 \%\end{array}$ & $\begin{array}{c}302 \pm 60[80-714] \\
78 \%\end{array}$ & NS \\
\hline Magnesium (mg) & $368 \pm 34$ [149-606] & $310 \pm 33[173-586]$ & NS \\
\hline \multicolumn{4}{|c|}{ Dietary supplementation } \\
\hline Calcium & $24 \%$ & $22 \%$ & NS \\
\hline Vitamin D & $35 \%$ & $28 \%$ & NS \\
\hline
\end{tabular}

Values are expressed as the mean \pm SEM. Ranges are in brackets. The $P$ value is for comparison between anorexia nervosa and control subjects by Student's $t$ test.

lower in the AN subjects compared with controls (AN, $0.98 \pm$ 0.01 ; control, $1.03 \pm 0.01 ; P=0.01)$. Duration of AN was $19 \pm$ 5 months, and duration of amenorrhea was $24 \pm 4$ months. Height was not significantly different between the groups. AN patients were of significantly lower weight and BMI. In the AN group, fat mass measured by DEXA was less than $50 \%$ that in controls (AN, $7.7 \pm 0.8$; control, $19.6 \pm 0.8 \mathrm{~kg} ; P<$ 0.0001 ), and percent body fat was substantially reduced (AN, $17.7 \pm 1.3 \%$; control, $33.5 \pm 1.3 \% ; P<0.0001)$. Lean body mass was also significantly lower in AN subjects (AN, $33.1 \pm$ 1.0; control, $37.1 \pm 1.0 \mathrm{~kg} ; P=0.01)$ even when controlled for height and body weight.

Historical assessment of activity level over the past year demonstrated that AN subjects were significantly more physically active than controls, with approximately twice as many hours of physical activity per week (AN, $17.0 \pm 2.2$; control, $9.4 \pm 2.2 \mathrm{~h}$ /week; $P=0.02$ ). Resting metabolic energy expenditure was significantly lower in AN subjects (AN, $1314 \pm 60$; control, $1587 \pm 60 \mathrm{KCal} /$ day). No subjects regularly smoked cigarettes or consumed alcohol.

\section{Nutritional data}

Analysis of intake by 4-day food record and diet history produced similar results; therefore, only the data for food records are provided in Table 2. Patients were in various stages of illness, and there was considerable variability in intake reported by the two groups. The major difference in dietary intake between the groups was reduced fat intake (AN, $41 \pm 7$; control, $65 \pm 7 \mathrm{~g} ; P=0.03$ ) and percentage of calories from fat (AN, $20 \pm 2 \%$; control, $28 \pm 2 \%$; $P=0.005$ ) in AN subjects. Fifty-three percent of AN patients and $67 \%$ of controls had a calcium intake less than the Recommended Daily Allowance of calcium despite calcium supplementation in approximately $23 \%$. In $53 \%$ of AN patients and $78 \%$ of controls, vitamin D intake was less than the Recommended Daily Allowance despite vitamin D supplementation in approximately $30 \%$ of subjects.

\section{Bone density data}

Bone density data are summarized in Table 3. Lumbar spine (L1-L4) BMD was significantly lower in the AN subjects (AN, $0.87 \pm 0.02$; control, $0.97 \pm 0.02 \mathrm{~g} / \mathrm{cm}^{2} ; P=0.004$ ). Lumbar bone mineral content (BMC) was also reduced in AN (AN, $45 \pm 2$; control, $51 \pm 2 \mathrm{~g} ; P=0.04)$, with lumbar area not different between the groups. In $42 \%$ of AN subjects lumbar BMD was more than 1 SD below the mean for the healthy, height- and BA-matched controls. Sixteen percent of AN subjects had a lumbar BMD more than 2 sD below the normal mean. Comparison of the subjects' lumbar spine BMD to the DEXA manufacturer normative data also dem- 
TABLE 3. Bone density and body composition data

\begin{tabular}{|c|c|c|c|c|}
\hline & $\begin{array}{l}\text { Anorexia nervosa } \\
\quad(\mathrm{n}=19)\end{array}$ & $\begin{array}{l}\text { Control } \\
(\mathrm{n}=19)\end{array}$ & $P$ value & $\begin{array}{l}P \text { value for ht-adjusted } \\
\text { BMD }\end{array}$ \\
\hline LBMD, L1-4 (g/ $\left.\mathrm{cm}^{2}\right)$ & $0.87 \pm 0.02$ & $0.97 \pm 0.02$ & 0.004 & 0.01 \\
\hline $\mathrm{LBMC}, \mathrm{L} 1-4(\mathrm{~g})$ & $45 \pm 2$ & $51 \pm 2$ & 0.04 & 0.03 \\
\hline Lateral spine BMD $\left(\mathrm{g} / \mathrm{cm}^{2}\right)$ & $0.68 \pm 0.02$ & $0.81 \pm 0.02$ & $<0.0001$ & 0.0002 \\
\hline Total BMD $\left(\mathrm{g} / \mathrm{cm}^{2}\right)$ & $1.01 \pm 0.02$ & $1.04 \pm 0.02$ & NS & NS \\
\hline TBMC (g) & $1700 \pm 53$ & $1889 \pm 53$ & 0.02 & 0.02 \\
\hline Fat $(\mathrm{kg})$ & $7.7 \pm 0.8$ & $19.6 \pm 0.8$ & $<0.0001$ & NA \\
\hline$\%$ Body fat & $17.7 \pm 1.3$ & $33.5 \pm 1.3$ & $<0.0001$ & NA \\
\hline Lean $(\mathrm{kg})$ & $33.1 \pm 1.0$ & $37.1 \pm 1.0$ & 0.01 & NA \\
\hline
\end{tabular}

All values are expressed as the mean \pm SEM. The $P$ value is for comparison between anorexia nervosa and control subjects by Student's $t$ test. NA, Not applicable.

onstrated that the AN group had significantly lower lumbar $\mathrm{BMD}$ (AN z-score, $-1 \pm 0.3$; controls z-score, $0.2 \pm 0.3 ; P=$ 0.002 ), with a $z$-score below -1 in $50 \%$, and below -2 in $21 \%$ of AN patients. The reduction in lateral spine BMD was even more severe in AN (AN, $0.68 \pm 0.02$; control, $0.81 \pm 0.02$ $\mathrm{g} / \mathrm{cm}^{2} ; P<0.0001$ ), with BMD more than 1 sD below the normal mean in $63 \%$ of patients and more than 2 sD below the normal mean in $26 \%$ of patients. Total body BMC (TBMC) was reduced in AN (AN, $1700 \pm 53$; control, $1889 \pm 53 \mathrm{~g} ; P=$ 0.02 ) and total body BMD (TBMD) was lower in AN, but not significantly. Differences in spinal BMD and TBMC remained significant when controlled for height. Similar differences in bone mineral apparent density were demonstrated (AN, $0.122 \pm 0.003 ;$ control, $0.132 \pm 0.003 \mathrm{~g} / \mathrm{cm}^{3} ; P=$ 0.02), using the formula of Katzman et al. (22).

In the control group, lean body mass was the single most significant predictor of lumbar BMC $(\mathrm{r}=0.75 ; P<0.0001)$ and lateral spine $(\mathrm{r}=0.55 ; P=0.003)$ and total $(\mathrm{r}=0.54 ; P=$ $0.004)$ BMD. These correlations remained significant when controlled for height and weight, but weight rather than lean body mass was a more significant determinant of lumbar BMD when controlled for height. The relationships between body weight, composition, BMC, and BMD were not present in AN. In AN, duration of illness was the most important determinant of lumbar BMD $(\mathrm{r}=-0.44 ; P=0.06)$ and BMC $(\mathrm{r}=-0.42 ; P=0.07)$ and lateral spine BMD $(\mathrm{r}=-0.59 ; P=$ 0.008 ), but not TBMD or TBMC. In addition, duration of amenorrhea $(\mathrm{r}=-0.58 ; P<0.05)$ was predictive of lateral spine BMD.

\section{Biochemical data}

TSH and serum ionized calcium and phosphorus were normal in all subjects. Calcium excretion in a 24-h urine collection was normal in all subjects, with the exception of one AN subject who was ingesting $2100 \mathrm{mg}$ calcium daily with a dietary supplement. The median 24-h urinary calcium was $144 \mathrm{mg}$ in both groups (range in AN, 71-450 mg; in control, 39-217 mg). UFC in a 24-h collection was not significantly different between groups (AN, $59 \pm 7$; control, $51 \pm$ $7 \mu \mathrm{g}$ ), although $33 \%$ of AN subjects (6 of 18) had modest elevations in UFC.

Serum PTH levels were normal in all subjects and were not different between the groups (Table 4). Serum 25-hydroxyvitamin D levels were lower in the control group, but normal in all subjects, and correlated with dietary vitamin $\mathrm{D}$ intake $(\mathrm{r}=0.41 ; P=0.03)$.
TABLE 4. Serum hormone concentrations

\begin{tabular}{lccc}
\hline & $\begin{array}{c}\text { Anorexia } \\
\text { nervosa } \\
(\mathrm{n}=11)\end{array}$ & $\begin{array}{c}\text { Control } \\
(\mathrm{n}=15)\end{array}$ & $P$ value \\
\hline 25-Hydroxyvitamin D (ng/mL) & $37 \pm 3$ & $29 \pm 3$ & 0.05 \\
PTH (pg/mL) & $24.8 \pm 3.6$ & $32.8 \pm 3.1$ & $\mathrm{NS}$ \\
Estradiol $(\mathrm{pg} / \mathrm{mL})$ & $16.2 \pm 1.9$ & $23.3 \pm 1.6$ & 0.01 \\
Total testosterone (ng/dL) & $23.6 \pm 3.4$ & $32.5 \pm 2.9$ & 0.06 \\
Free testosterone (pg/mL) & $0.70 \pm 0.17$ & $1.36 \pm 0.14$ & 0.01 \\
DHEAS $(\mu \mathrm{g} / \mathrm{dL})$ & $223 \pm 31$ & $212 \pm 26$ & $\mathrm{NS}$ \\
IGF-I $(\mathrm{ng} / \mathrm{mL})$ & $219 \pm 41$ & $511 \pm 35$ & $<0.0001$ \\
Leptin $(\mathrm{ng} / \mathrm{mL})$ & $2.9 \pm 2.1$ & $16.5 \pm 1.8$ & $<0.0001$
\end{tabular}

Serum hormone data in mature (bone age of $15 \mathrm{yr}$ or greater) subjects. Values are expressed as the mean \pm SEM. The $P$ value if for comparison between anorexia nervosa and control subjects by Student's $t$ test.

Serum $\mathrm{E}_{2}$ levels were significantly reduced, even in comparison with controls sampled in the early follicular phase (Table 4). There was a trend toward lower total $\mathrm{T}$ levels in $\mathrm{AN}$, and free $\mathrm{T}$ levels were markedly reduced (AN, $0.70 \pm$ 0.17 ; control, $1.36 \pm 0.14 \mathrm{pg} / \mathrm{mL} ; P=0.006$ ), with levels below the lower limit of detection of the assay in $82 \%$ of AN subjects.

Serum IGF-I levels were reduced significantly in AN, to less than $50 \%$ of those in the control subjects (AN, $219 \pm 41$; control, $511 \pm 35 \mathrm{ng} / \mathrm{mL} ; P<0.0001)$. Leptin was also markedly reduced in $\mathrm{AN}(\mathrm{AN}, 2.9 \pm 2.1$; control, $16.5 \pm 1.8 \mathrm{ng} / \mathrm{mL}$; $P<0.0001$ ), to less than $20 \%$ of control levels. In all subjects, IGF-I levels correlated highly with nutritional status, including BMI $(\mathrm{r}=0.73 ; P<0.0001)$, percent body fat $(\mathrm{r}=0.61 ; P=$ $0.0008)$, lean body mass $(\mathrm{r}=0.49 ; P=0.005)$, and leptin $(\mathrm{r}=$ $0.80 ; P<0.0001)$. In contrast, there was no relationship between IGF-I and gonadal steroid concentrations. In stepwise regression analysis including all anthropometric and biochemical measurements, leptin accounted for $65 \%$ of the variation in IGF-I levels $\left(\mathrm{r}^{2}=0.65 ; P<0.00001\right)$. Leptin was highly dependent on fat mass $(\mathrm{r}=0.78 ; P<0.0001)$.

Bone turnover marker results are summarized in Table 5 and Fig. 1. OC and BSAP were significantly lower in AN patients than in normal subjects. DPD and NTX were not significantly different between the groups. However, there was a trend toward lower NTX levels in the AN group. There was a strong correlation between IGF-I and OC in AN subjects $(\mathrm{r}=0.71 ; P=0.01 ;$ Fig. 2$)$, whereas in the control group a similar trend was found, but the correlation did not reach statistical significance $(\mathrm{r}=0.46 ; P=0.07)$. In stepwise re- 
TABLE 5. Bone turnover markers

\begin{tabular}{lccc}
\hline & $\begin{array}{c}\text { Anorexia } \\
\text { nervosa } \\
(\mathrm{n}=11)\end{array}$ & $\begin{array}{c}\text { Control } \\
(\mathrm{n}=15)\end{array}$ & $P$ value \\
\hline OC $(\mathrm{ng} / \mathrm{mL})$ & $39.1 \pm 6.4$ & $59.2 \pm 5.2$ & 0.02 \\
$\mathrm{BSAP}(\mathrm{U} / \mathrm{L})$ & $27.9 \pm 4.0$ & $40.6 \pm 3.4$ & 0.02 \\
$\mathrm{PICP}(\mathrm{ng} / \mathrm{mL})$ & $139 \pm 12$ & $154 \pm 10$ & $\mathrm{NS}$ \\
$\mathrm{DPD}(\mathrm{nmol} / \mathrm{mmol}$ creatinine) & $13.4 \pm 1.4$ & $15.1 \pm 1.2$ & $\mathrm{NS}$ \\
NTX (nmol BCE/mmol & $138 \pm 25$ & $200 \pm 21$ & $\mathrm{NS}$ \\
$\quad$ creatinine) & & & \\
\hline
\end{tabular}

Bone turnover markers in mature (bone age of $15 \mathrm{yr}$ or more) subjects. Values are expressed as the mean \pm SEM. The $P$ value if for comparison between anorexia nervosa and control subjects by Student's $t$ test.

gression analysis, IGF-I accounted for $72 \%\left(\mathrm{r}^{2}=0.72 ; P=\right.$ $0.002)$, and IGF-I and free T together accounted for $95 \%\left(\mathrm{r}^{2}\right.$ $=0.95 ; P=0.0006)$, of the variation in OC levels in AN. There was a similar strong relationship between IGF-I and BSAP in the AN group ( $\mathrm{r}=0.73 ; P=0.01 ; \mathrm{Fig}$. 2 ) and the control group $(\mathrm{r}=0.59 ; P=0.02)$. In stepwise regression analysis, IGF-I was the only significant predictor of BSAP, accounting for $53 \%$ $\left(\mathrm{r}^{2}=0.53 ; P=0.01\right)$ of the variation in BSAP in AN and $35 \%$ $\left(\mathrm{r}^{2}=0.35 ; P=0.01\right)$ in controls.

\section{Adult height}

Subjects in the mature group, who had a minimum BA of $15 \mathrm{yr}$, were determined to be at adult height. When adult height was compared to midparental target height, height was significantly reduced in the AN group, on the average $3.0 \mathrm{~cm}$ below midparental height $(\mathrm{AN},-3.0 \pm 1.0$; control, $0.2 \pm 0.9 \mathrm{~cm} ; P=0.02)$. Furthermore, only one subject in the AN group exceeded her midparental target height, compared with eight $(53 \%)$ control subjects.

\section{Discussion}

In this study, we have characterized bone density and bone metabolism in adolescent girls with AN compared with those in BA-matched controls. Bone formation indices and bone density are significantly reduced in adolescents with AN. Moreover, low bone formation in this population was strongly associated with markedly diminished IGF-I, a nutritionally dependent endogenous bone trophic factor. In addition, we have shown that in these osteopenic girls the decrease in bone formation is uncoupled from bone resorption.

Our data demonstrate that spinal osteopenia is common in adolescent girls with AN compared with a group of BA- and CA-matched healthy adolescents. In the patient group, $42 \%$ of AN subjects had a lumbar spine BMD more than 1 SD, and $16 \%$ had a lumbar spinal BMD more than 2 SD, below the mean of the BA- and height-matched controls despite an average duration of illness of only $1.5 \mathrm{yr}$. The results of lateral spine BMD, which may be more representative of trabecular bone (23), demonstrated even more severe osteopenia, with BMD more than $1 \mathrm{sD}$ below the mean in $63 \%$ and more than 2 SD in $26 \%$ of AN patients compared with controls. Furthermore, we obtained similar results for height-adjusted and bone mineral apparent density calculations, suggesting that the low BMD was not an artifact of size.
Previous studies of bone metabolism in adolescents with AN have been limited by the small numbers of subjects, inclusion of a broad age range, and lack of information about specific biochemical markers of bone turnover, including measures of both formation and resorption. To assess further the mechanisms of reduced BMD in AN we characterized bone metabolism in adolescents with AN compared with that in a CA- and BA-matched group of healthy adolescents. Studies of adult women with AN demonstrate a severe imbalance in bone turnover, with a decrease in markers of bone formation combined with an increase in markers of bone resorption (24). However, data obtained from women with AN cannot be extrapolated to adolescent patients who are in an active period of bone growth and mineral accretion as well as remodeling. Abrams et al. demonstrated that adolescents with AN have decreased calcium absorption and increased urinary calcium excretion; however, bone markers were not measured (9). Saggese et al. reported low levels of carboxylterminal propeptide of type 1 procollagen, a bone formation marker, in six adolescent AN patients ranging from 11-21 yr of age, but did not investigate other markers of formation or markers of resorption in these patients (10).

Matching patients with controls based on stage of maturation is critical in the evaluation of bone metabolism, as both bone formation and resorption markers change dramatically with the transition from early (Tanner stage 2-3) to late (Tanner stage $4-5)$ puberty $(15,16)$. Furthermore, levels of bone formation and resorption remain above adult levels even in mature (Tanner stage 5) adolescents (15). We chose to classify maturation in adolescents based on BA because assessment of Tanner stage in adolescents with AN who are hypoestrogenemic is difficult and likely to be inaccurate. In our study, all healthy controls who had a BA of $15 \mathrm{yr}$ or greater had Tanner stage 4-5 development and therefore were classified as mature. In contrast, $35 \%$ of AN patients with a mature BA had what appeared clinically to be Tanner stage 3 breast tissue. Therefore, Tanner staging as a measure of pubertal maturation in AN can be inaccurate, whereas BA provides a more objective classification.

Bone formation indexes, OC and BSAP, were significantly reduced in mature adolescents with $\mathrm{AN}$ in contrast to those in healthy mature adolescents. In contrast, markers of bone resorption, DPD and NTX, were not significantly different, although there was a trend toward lower NTX in AN subjects. Therefore, in healthy adolescents, high levels of bone formation and resorption were seen. In contrast, patients with AN had low bone formation with normal resorption. Although biochemical markers are indirect measures of bone growth and remodeling, resorption indexes are generally thought to reflect degradation of existing bone, whereas formation indices in adolescents are thought to reflect skeletal growth and mineralization. We speculate that in a low metabolic state such as AN, remodeling continues, and bone formation associated with growth and bone mineral accumulation is reduced. We were unable to measure bone metabolism in the immature adolescents due to insufficient numbers of subjects and therefore could not determine whether the balance of bone formation and resorption is also altered in immature patients with AN. Further studies in younger patients will provide insight as to whether reduced 

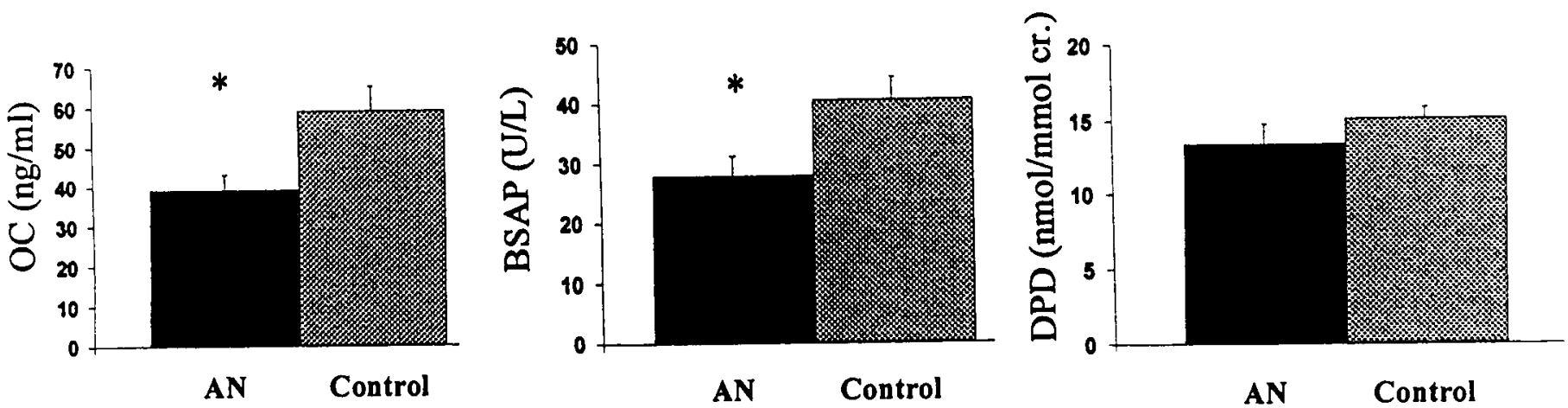

Fig. 1. Comparison of bone turnover markers in mature subjects with $\mathrm{AN}(\mathrm{n}=11)$ and controls $(\mathrm{n}=15)$. Results are the mean \pm SEM. OC and BSAP, * $P=0.02$; deoxypyridinoline (DPD), $P=$ NS. The $P$ value is for comparison of AN subjects $v s$. BA-matched controls.
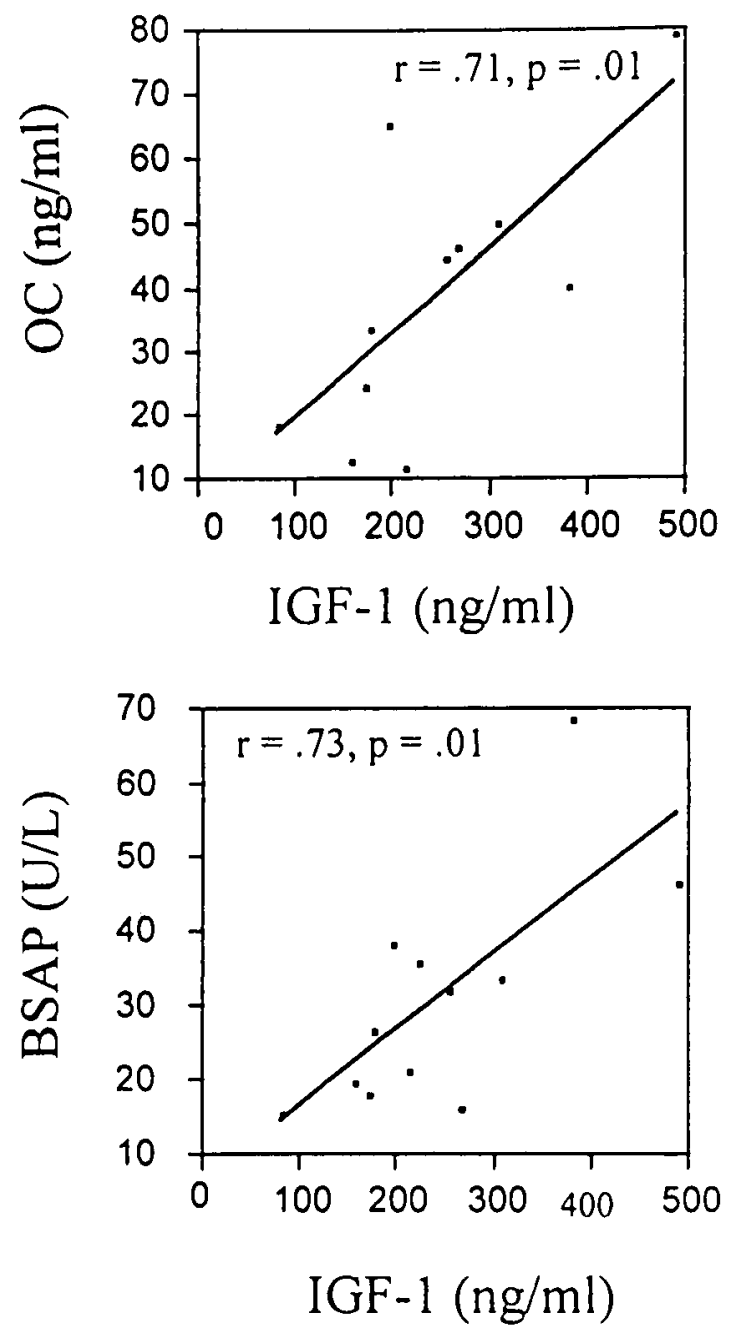

FIG. 2. Correlation between IGF-I and bone formation markers in mature subjects (BA, 15 yr or greater) with $\mathrm{AN}(\mathrm{n}=11)$.

bone formation in AN is dependent on the stage of maturation.

The primary correlate of bone formation in AN was the level of IGF-I, which was markedly reduced in AN subjects, in contrast to the high levels expected and found in normal adolescents. IGF-I functions as a bone trophic hormone, which positively affects bone growth and bone turnover by stimulating osteoblasts, collagen synthesis, and longitudinal bone growth $(25,26)$. Low levels of serum IGF-I are present in undernutrition and correlate with low BMI in $\mathrm{AN}(24,27$, 28). We found a high correlation between all indexes of nutritional status, including body composition variables and particularly leptin, with IGF-I levels, indicting that undernutrition is a major cause of reduced IGF-I levels in adolescents with AN. These data indicate that IGF-I deficiency due to undernutrition could significantly contribute to low bone formation in adolescents with AN.

In healthy adolescents, $E_{2}$ is thought to contribute significantly to bone mineral acquisition, either by acting directly on bone or by stimulating other mediators of bone growth $(12,29)$. In this study, in contrast to other studies $(15,29)$, we determined bone turnover during the early follicular phase of the menstrual cycle when $E_{2}$ is at low levels to control for effects of cycle stage on bone metabolism. Significant effects of the menstrual cycle on OC and BSAP have been described in women, showing that osteoblast activity is higher during the luteal phase (30). We have described a reduction in bone formation between AN and controls at a point in the menstrual cycle when levels of bone formation in controls are relatively reduced. Therefore, the degree of reduction in indexes of bone formation might be even greater after the follicular phase.

Hypoestrogenemia has been proposed as a contributing factor to the low bone density in AN, because primary or secondary amenorrhea is a nearly universal feature. In adolescents, lower lumbar bone density is seen in amenorrheic teens compared with those with normal menses, but is not significant when patients are controlled for body weight (31, 32). In fact, gains in bone density may precede the return of menses in patients recovering from AN (4). Estrogen treatment in young women with AN has not caused improvement in bone density in a randomized, prospective trial (33), but has not been investigated in adolescent AN patients. In our study, duration of illness was the most predictive of AP and lateral spine BMD. Our data suggest that nutritional status may be an independent determinant of bone density.

This study demonstrates that in addition to estrogen deficiency, adolescents with AN have markedly diminished levels of total and free $\mathrm{T}$, with free $\mathrm{T}$ undetectable in the majority of patients. In contrast, dehydroepiandrosterone sulfate levels were not different between the groups, suggesting a relatively greater deficiency in gonadal than ad- 
renal androgen production. These data are in agreement with recent data demonstrating that in pubertal adolescents the ovaries are the major source of serum $\mathrm{T}$, in contrast to prepuberty when the adrenals are the primary source (34). Positive correlations between total and free $\mathrm{T}$ and bone formation (OC) have been demonstrated in adult women during the normal menstrual cycle, including the follicular phase (35), although this has not been reported in adolescents. In our group of AN adolescents, OC was determined in part by free $\mathrm{T}$ in stepwise regression analysis.

Nutritional factors, particularly body weight and lean body mass, are critical determinants of bone mass in adolescent girls $(36,37)$. Our data demonstrate markedly reduced fat mass, percent body fat, and lean body mass in AN adolescents even when controlled for height and weight. In healthy normal weight and obese children (5-18 yr), lean body mass had the highest correlation with total bone mineral content (36). Bachrach et al. reported that BMI correlated highly with bone density when adolescents with AN and controls were analyzed together, but in the AN group alone there was no correlation (3). In our study, lean body mass was the only body composition variable that contributed significantly to total and regional (total and lumbar BMC and lateral spine BMD) bone density in healthy adolescent girls. However, determinants of bone mass in AN may differ from those in healthy girls. Similar to the relationship between BMI and BMD described by Bachrach et al. (3), our data show that when the AN and control groups were analyzed together, lean body mass significantly correlated with lumbar $\operatorname{BMD}(\mathrm{r}=0.49 ; P=0.005)$; however, in the AN group alone this relationship was not present.

An important finding in our study is that dietary calcium and vitamin $\mathrm{D}$ deficiency are prevalent in our study population of both AN patients and normal adolescent girls. As has been reported in other studies of adolescent girls $(38,39)$, a majority of girls were deficient in dietary calcium intake during a time when calcium requirements are maximal (40), even though $23 \%$ of all girls studied were receiving dietary supplements. Calcium intake has been shown to correlate with bone density in healthy children and adolescents (11, 41 ), and calcium supplementation has been shown to increase bone density in studies of healthy adolescents, although the effect may be dependent on pubertal stage (38, 39). Most of our adolescent subjects also had deficient vitamin D intake. Although all of our study subjects had normal serum 25-hydroxyvitamin D and PTH levels, the AN group had higher 25-hydroxyvitamin D levels that correlated with vitamin D intake. Our data indicate that most adolescent girls may not get sufficient amounts of these important nutrients with food intake alone; therefore, routine supplementation in many adolescent girls may be warranted. No correlation between calcium intake and BMD in adolescents with AN was demonstrated in this study, and it is unknown whether BMD could be improved by calcium and vitamin D supplementation in adolescents with AN.

Other factors that may affect BMD, including UFC and exercise, were investigated, but did not impact BMD in this study. We did not find a relationship between UFC and lumbar BMD as has been described in adult women with AN (6), although $33 \%$ of the AN patients had elevations in UFC.
Physical activity, particularly weight-bearing exercise, is known to have positive effects on bone density in children and adolescents $(11,41)$, although heavy exercise during adolescence may lead to delayed puberty and low bone density (42). In this study, physical activity was significantly higher in the AN group, probably contributing to their low weight and amenorrhea. However, there was no relationship between amount of physical activity and BMD in either group. Some patients may have relatively normal BMD despite low weight due to a previous environmental exposure (i.e. prepubertal exercise) or inherited factors, such as vitamin D receptor or COLA1A polymorphisms, which may be protective (43-46) but were not systematically evaluated in this study.

Adolescents with AN have been reported to have decreased linear growth rate and adult height $(47,48)$; however, adult height in this population of patients in comparison with genetic target height has not been reported. We found that mature AN adolescents were, on the average, $3.0 \mathrm{~cm}$ below their genetic target height compared with healthy adolescents who, on the average, reached their genetic target height. The reason for reduced growth in AN could not be evaluated in this cross-sectional cohort and will require longitudinal study, but reduced circulating IGF-I resulting in low bone formation is one potential mechanism.

This is the first study to describe low bone formation in BA- and CA-matched adolescents with AN, in whom bone formation is highly correlated with serum levels of IGF-I. Low bone formation may result in reduced peak bone accumulation and eventual severe osteopenia, as seen in adult women with AN. Low IGF-I due to undernutrition in addition to gonadal steroid deficiency during the critical adolescent period may be an important factor contributing to the pathogenesis of osteopenia in AN.

\section{Acknowledgments}

The investigators wish to thank the skilled research nurses on the General Clinical Research Center for their dedicated patient care, Ellen Anderson and the Clinical Research Center nutrition staff for assessment of dietary intake, and Mr. Gregory Neubauer for technical assistance.

\section{References}

1. Wakeling A. 1996 Epidemiology of anorexia nervosa. Psychiatry Res. 62:3-9.

2. Hsu, LKG. 1996 Epidemiology of the eating disorders. Psychiatric Clin North Am. 19:681-700

3. Bachrach LK, Guido D, Katzman D, Litt IF, Marcus R. 1990 Decreased bone density in adolescent girls with anorexia nervosa. Pediatrics. 86:440-447.

4. Bachrach LK, Katzman DK, Litt IF, Guido D, Marcus R. 1991 Recovery from osteopenia in adolescent girls with anorexia nervosa. J Clin Endocrinol Metab. 72:602-606.

5. Kooh SW, Noriega E, Leslie K, Muller C, Harrison JE. 1996 Bone mass and soft tissue composition in adolescents with anorexia nervosa. Bone. 19:181-188.

6. Biller BMK, Saxe V, Herzog DB, Rosenthal DI, Holzman S, Klibanski A. 1989 Mechanisms of osteoporosis in adult and adolescent women with anorexia nervosa. J Clin Endocrinol Metab. 68:548-554.

7. Brotman AW, Stern TA. 1985 Osteoporosis and pathologic fractures in anorexia nervosa. Am J Psychiatry. 142:495-496.

8. Herzog W, Minne H, Deter C, et al. 1993 Outcome of bone mineral density in anorexia nervosa patients 11.7 years after first admission. J Bone Miner Res. 8:597-605

9. Abrams SA, Silber TJ, Esteban NV, et al. 1993 Mineral balance and bone turnover in adolescents with anorexia nervosa. J Pediatr. 123:326-31.

10. Saggese G, Bertelloni S, Baroncelli GI, DiNero G. 1992 Serum levels of carboxyterminal propeptide of type 1 procollagen in healthy children from 1 st year of life to adulthood and in metabolic bone diseases. Eur J Pediatr. 151:764-820. 
11. Rubin K, Schirduan V, Gendreau P, Sarfarazi M, Dalsky G. 1993 Predictors of axial and peripheral bone mineral density in healthy children and adolescents, with special attention to the role of puberty. J Pediatr. 123:863-870.

12. Glastre C, Braillon P, David L, Cochat P, Meunier PJ, Delmas PD. 1990 Measurement of bone mineral content of the lumbar spine by dual energy $\mathrm{x}$-ray absorptiometry in normal children: correlations with growth parameters. J Clin Endocrinol Metab. 70:1330-1333.

13. Hammer LD, Kraemer HC, Wilson DM, et al. 1991 Standardized percentile curves of body mass index for children and adolescents. AJDC. 145:259-263.

14. Greulich WW, Pyle SI. 1950 Radiographic atlas of skeletal development of the hand, and wrist. 2nd Ed. Stanford: Stanford University Press.

15. Blumsohn A, Hannon RA, Wrate R, et al. 1994 Biochemical markers of bone turnover in girls during puberty. Clin Endocrinol. 40:663-670.

16. Tobiume H, Kanzaki S, Hida S, et al. 1997 Serum bone alkaline phosphatase isoenzyme levels in normal children and children with growth hormone deficiency: a potential marker for bone formation and response to GH therapy. J Clin Endocrinol Metab. 82:2056-2061.

17. Case Records of the Massachusetts General Hospital. 1992 Weekly clinicopathological exercises. Normal reference laboratory values. N Engl J Med. 327:718-724

18. Ellis KJ, Shypailo RJ, Pratt J, Wilson WG. 1994 Accuracy of dual-energy x-ray absorptiometry for body composition measurements in children. Am J Clin Nutr. 60:660-665.

19. Mazess RB, Barden HS, Bisek JP, Hanson J. 1990 Dual energy x-ray absorptiometry for total -body and regional bone mineral and soft tissue composition. Am J Clin Nutr. 51:1106-1112.

20. Ritz R, Cunningham J. 1993 Indirect calorimetry. In: Kacmarek RM, Hess D, Stoller JK, eds. Monitoring in respiratory care. St. Louis: Mosby-Yearbook; 407-441.

21. Aaron DJ, Kriska AM, Dearwater SR, et al. 1995 Reproducibility and validity of an epidemiologic questionnaire to assess past year physical activity in adolescents. Am J Epidemiol. 142:191-201.

22. Katzman DK, Bachrach LK, Carter DC, Marcus R. 1991 Clinical and anthropometric correlates of bone mineral acquisition in healthy adolescent girls. J Clin Endocrinol Metab. 73:1332-1339.

23. Finkelstein JS, Cleary RL, Butler JP, et al. 1994 A Comparison of lateral vs. anterior-posterior spine dual energy $x$-ray absorptiometry for the diagnosis of osteopenia. J Clin Endocrinol Metab. 78:724-730.

24. Grinspoon S, Baum H, Lee K, Anderson E, Herzog D, Klibanski A. 1996 Effects of short-term recombinant human insulin-like growth factor 1 administration on bone turnover in osteopenic women with anorexia nervosa. J Clin Endocrinol Metab. 81:3864-3870.

25. Hock JM, Centrella M, Canalis E. 1988 Insulin-like growth factor 1 has independent effects on bone matrix formation and cell replication. Endocrinology. 122:254-260.

26. Skottner A, Arrhenius-Nyberg V, Kanje M, Fryklund L. 1990 Anabolic and tissue repair functions of recombinant insulin-like growth factor 1. Acta Paediatr Scand. 367(Suppl):633-637.

27. Golden NH, Kreitzer P, Jacobson MS, et al. 1994 Disturbances in growth hormone secretion and action in adolescents with anorexia nervosa. J Pediatr. 125:655-660.

28. Rappaport R, Prevot C, Czernichow P. 1980 Somatomedin activity and growth hormone secretion. I. Changes related to body weight in anorexia nervosa. Acta Paediatr Scand. 69:37-41.
29. Cadogan J, Blumsohn A, Barker ME, Eastell R. 1998 A longitudinal study of bone gain in pubertal girls: anthropometric and biochemical correlates. J Bone Miner Res. 13:1602-1612.

30. Nielsen HK, Brixen K, Bouillon R, Mosekilde L. 1990 Changes in biochemical markers of osteoblastic activity during the menstrual cycle. J Clin Endocrinol Metab. 70:1431-1437.

31. White CM, Hergenroeder AC, Klish WJ. 1992 Bone mineral density in 15-21 year old eumenorrheic and amenorrheic subjects. AJDC. 146:31-35.

32. Hergenroeder AC. 1995 Bone mineralization, hypothalamic amenorrhea, and sex steroid therapy in female adolescents and young adults. J Pediatr. 126:683-689.

33. Klibanski A, Biller BMK, Schoenfeld DA, Herzog DB, Saxe VC. 1995 The effects of estrogen administration on trabecular bone loss in young women with anorexia nervosa. J Clin Endocrinol Metab. 80:898-904.

34. Ankarberg C, and Norjavaara E. 1999 Diurnal rhythm of testosterone secretion before and throughout puberty in healthy girls: correlation with $17 \beta$-estradiol and dehydroepiandrosterone sulfate. J Clin Endocrinol Metab. 84:975-984.

35. Massafra C, De Felice C, Agnusdei DP, Gioia D, Bagnoli F. 1999 Androgen and osteocalcin during the menstrual cycle. J Clin Endocrinol Metab. 84:971-974.

36. Manzoni P, Brambilla P, Pietrobelli A, et al. 1996 Influence of body composition on bone mineral content in children and adolescents. Am J Clin Nutr. 64:603-607.

37. Ellis KJ, Abrams SA, Wong WW. 1997 body composition of a young, multiethnic female population. Am J Clin Nutr. 65:724-731.

38. Lloyd T, Andon MB, Rollings N, et al. 1993 Calcium supplementation and bone mineral density in adolescent girls. JAMA. 270:841-844

39. Johnston CC, Miller JZ, Slemenda CW, et al. 1992 calcium supplementation and increases in bone mineral density in children. N Engl J Med. 327:82-87.

40. Martin AD, Bailey DA, McKay H, Whiting S. 1997 Bone mineral and calcium accretion during puberty. Am J Clin Nutr. 66:611-615.

41. Ruiz JC, Mandel C, Garabedian M. 1995 Influence of spontaneous calcium intake and physical exercise on the vertebral and femoral bone mineral density of children and adolescents. J Bone Miner Res. 95:675-679.

42. Frisch, RE, Gotz- Welbergen AV, McArthur JW, et al. 1981 Delayed menarche and amenorrhea of college athletes in relation to age and onset of training. JAMA. 246:1559-1563.

43. Bass S, Pearce G, Bradney M, et al. 1998 Exercise before puberty may confer residual benefits in bone density in adulthood: studies in active prepubertal and retired female gymnasts. J Bone Miner Res. 13:500-507.

44. Sainz J, Van Tornout JM, Loro L, Sayre J, Roe TF, Gilsanz V. 1997 Vitamin $\mathrm{D}$ receptor gene polymorphisms and bone density in prepubertal American girls of Mexican descent. N Engl J Med. 337:77-82.

45. Ferrari SL, Rizzoli R, Slosman DO, Bonjour JP. 1998 Do dietary calcium and age explain the controversy surrounding the relationship between bone mineral density and vitamin d receptor gene polymorphisms? J Bone Miner Res. 13:363-370.

46. Sainz J, Van Tornout JM, Sayre J, Kaufman F, Gilsanz V. 1999 Association of collagen type $1 \alpha 1$ gene polymorphism with bone density in early childhood. J Clin Endocrinol Metab. 84:853-855.

47. Nussbaum M, Baird D, Sonnenblick M, et al. 1985 Short stature in anorexia nervosa patients. J Adolesc Health Care. 6:453-455.

48. Russell GFM. 1985 Premenarchal anorexia and its sequelae. J Psychiatr Res 19:363-369. 